\title{
COMUNICAÇÃO
}

\section{PRÉ-ACLIMATIZAÇÃO In Vitro DE ABACAXI-ORNAMENTAL}

\author{
In vitro pre-acclimatization of ornamental pineapple
}

\author{
Yohana de Oliveira ${ }^{1}$, Justina Inês Anselmini², Francine Lorena Cuquel$^{2}$, \\ Fernanda Pinto ${ }^{3}$, Marguerite Quoirin ${ }^{2}$
}

\begin{abstract}
RESUMO
O abacaxi ornamental (Ananas bracteatus Schult. f.) é bastante utilizado em composições paisagísticas para delimitar áreas ou canteiros. A micropropagação permite obter altas taxas de multiplicação, podendo ser uma alternativa viável e vantajosa de propagação vegetativa, visto que a demanda por esta espécie vem aumentando, tanto no mercado nacional quanto no internacional. Neste trabalho objetivou-se avaliar a influência de diferentes irradiâncias e concentrações de sacarose durante o enraizamento in vitro, sobre a sobrevivência das mudas na fase de aclimatização. Para tanto, foram testadas diferentes concentrações de sacarose $\left(0,10,20 \mathrm{e} 30 \mathrm{~g} \mathrm{~L}{ }^{-1}\right)$ no meio de enraizamento, bem como duas irradiâncias $\left(22,9\right.$ e $\left.66,9 \mathrm{mmol} \mathrm{m}^{-2} \mathrm{~s}^{-1}\right)$ em sala de crescimento. O melhor resultado em termos de enraizamento foi obtido no meio de cultura contendo $30 \mathrm{~g} \mathrm{~L}^{-1}$ de sacarose sob irradiância de $66,9 \mathrm{mmol} \mathrm{m}^{-2} \mathrm{~s}^{-1}$. Após a fase de enraizamento in vitro, as plantas foram transferidas para casa de vegetação e mantidas sob nebulização intermitente por 60 dias. Os resultados de sobrevivência aos 30 e 60 dias não diferiram estatisticamente para os dois níveis de irradiância testados. Entretanto, para concentrações de sacarose, a testemunha apresentou sobrevivência inferior (50\%) diferindo estatisticamente dos demais tratamentos que foram semelhantes entre si (95 a 100\%).
\end{abstract}

Termos para indexação: Ananas bracteatus, micropropagação, planta ornamental.

\begin{abstract}
Ornamental pineapple (Ananas bracteatus Schult. f.) is often used in landscape compositions in order to limit areas or borders. Micropropagation allows high multiplication rates and may be an interesting technique of vegetative propagation in order to meet the need of plants of this species that is rising on national and international markets. The objective of this study was to determine the effect of several light irradiances and sucrose concentrations during in vitro rooting on survival during the acclimatization stage. Several concentrations of sucrose $\left(0,10,20\right.$ or $\left.30 \mathrm{~g} \mathrm{~L}^{-1}\right)$ in the rooting medium and two light irradiances $\left(22.9\right.$ and $\left.66.9 \mathrm{mmol} \mathrm{m}^{-2} \mathrm{~s}^{-1}\right)$ in the culture room were tested. The best results of rooting were obtained on culture medium containing $30 \mathrm{~g} \mathrm{~L}^{-1}$ sucrose under an irradiance of $66.9 \mathrm{mmol} \mathrm{m}^{-2} \mathrm{~s}^{-1}$. The plants were then transferred to the greenhouse and cultured under intermittent mist for 60 days. There was no significant difference among the results of survival under the two irradiances tested. However, for sucrose concentrations, the survival rate of the control (50\%) was statistically inferior to that of the other treatments that were similar among them (95 and $100 \%)$.
\end{abstract}

Index terms: Ananas bracteatus, micropropagation, ornamental plant.

\section{(Recebido em 29 de maio de 2008 e aprovado em 13 de fevereiro de 2009)}

Ananas bracteatus Schult. f. é uma espécie nativa pertencente à família Bromeliaceae, bastante utilizada em composições paisagísticas, para delimitar áreas ou canteiros. O abacaxi ornamental é também exportado, sendo muito utilizado na Europa e nos Estados Unidos. De acordo com Baima (2005), no Ceará as exportações de abacaxi ornamental têm como principais destinos Holanda, Alemanha e Portugal.

Normalmente, os plantios de abacaxi ornamental têm sido feitos com mudas propagadas vegetativamente (Borges et al., 2003). Entretanto, a micropropagação pode ser uma alternativa viável de propagação vegetativa quando comparada a outras técnicas, pois permite obter maior taxa de multiplicação, maior qualidade fitossanitária e estabilidade genética, em menor período de tempo durante o ano todo (Correia et al., 1999). O sucesso da micropropagação está na habilidade em propagar a cultura em larga escala, a um baixo custo e com alto nível de sobrevivência. Ao serem aclimatizadas, as plantas cultivadas in vitro podem apresentar alta mortalidade (Hazarika, 2006), o que pode inviabilizar todas as etapas anteriores da micropropagação.

Vários são os fatores que podem contribuir para um bom índice de sobrevivência das mudas

${ }^{1}$ Universidade Federal do Paraná/UFPR - Rua dos Funcionários, 1540 - Bairro Juvevê - Cx. P. 19061 - 81531-990 - Curitiba, PR - yohana@ufpr.br 'Universidade Federal do Paraná/UFPR - Curitiba, PR

${ }^{3}$ Faculdades Integradas do Brasil - Curitiba, PR 
micropropagadas e, consequentemente, para o sucesso da aclimatização. Silva et al. (2006) obtiveram taxas de sobrevivência entre 63,3 e 91,6\% em Dyckia maritima Baker (Bromeliaceae) aos 120 dias da aclimatização, demonstrando que, dependendo do tratamento utilizado, a resposta da sobrevivência varia consideravelmente.

Os tratamentos in vitro também podem refletir na capacidade das plantas suportarem mudanças bruscas de ambiente que a passagem para a casa-de-vegetação ocasiona. Dentre estes, a necessidade de sacarose no período final do cultivo é bastante discutida por vários autores. Conforme Kozai (1991), na presença de açúcar, as plantas não desenvolvem capacidade fotoautótrofica, podendo levar a um crescimento reduzido e consequente morte das mudas, durante a fase de aclimatização. Entretanto, alguns sugerem até mesmo aumentar o nível de sacarose na fase anterior à aclimatização, pois esse précondicionamento causaria um incremento nas reservas de carboidratos armazenadas pelas folhas, aumentando assim, a energia disponível para as plântulas durante o processo de aclimatação.

Entre os diversos componentes do ambiente, a luz é primordial para o crescimento das plantas, fornecendo sinais que regulam o desenvolvimento. Dessa forma, modificações nos níveis de irradiância podem condicionar diferentes respostas fisiológicas em suas características bioquímicas, anatômicas e de crescimento (Atroch et al., 2001). Para Economou \& Read (1987), a irradiância, além de influenciar o crescimento e a proliferação das brotações, pode afetar diretamente a formação de raízes e, quando em excesso, reduzir a formação das mesmas.

Diante do exposto, deve-se minimizar ao máximo as diferenças entre os dois ambientes, além de favorecer nas plantas in vitro a iniciação de um mecanismo mixotrófico, intermediário entre os mecanismos heterotróficos e autotróficos (Pasqual, 2001). Nesse sentido, conduziu-se este trabalho com o objetivo de avaliar a influência de diferentes concentrações de sacarose no meio de cultura e diferentes níveis de irradiância na fase de enraizamento in vitro, na sobrevivência durante a aclimatização de material micropropagado de Ananas bracteatus.

Plantas de $A$. bracteatus, provenientes do $7^{\circ}$ subcultivo in vitro, foram doadoras de explantes para o experimento. As plantas encontravam-se em meio de multiplicação (MS líquido acrescido de $0,5 \mathrm{mg} \mathrm{L}^{-1}$ de BAP), onde cada frasco continha 5 explantes, mantidos em sala de crescimento sob fotoperíodo de 16 horas, temperatura de $25 \pm 1^{\circ} \mathrm{C}$ e irradiância de $46,8 \mathrm{mmol} \mathrm{m}^{-2} \mathrm{~s}^{-1}$, fornecida por duas lâmpadas fluorescentes do tipo "luz branca".

Brotações de $A$. bracteatus com aproximadamente $4 \mathrm{~cm}$ de altura, foram cultivadas em meio de enraizamento. Esse meio continha a metade da concentração dos sais do meio MS (Murashige \& Skoog, 1962), as vitaminas completas, $1,0 \mathrm{mg} \mathrm{L}^{-1}$ de AIB e $6 \mathrm{~g} \mathrm{~L}^{-1}$ de ágar. $\mathrm{O} \mathrm{pH}$ dos meios foi ajustado em 5,8 antes da autoclavagem em $120^{\circ}$ $\mathrm{C}$ por $20 \mathrm{~min}$. Os tratamentos consistiram na variação da concentração de sacarose $\left(0,10,20\right.$ e $\left.30 \mathrm{~g} \mathrm{~L}^{-1}\right)$ no meio de cultura e dois níveis de irradiância $\left(22,9\right.$ e $\left.66,9 \mu \mathrm{mol} \mathrm{m-}{ }^{2} \mathrm{~s}^{-1}\right)$ fornecidos por 1 ou 4 lâmpadas fluorescentes do tipo "luz branca" de $1,18 \mathrm{~m}$ de comprimento, por prateleira com área de $1,06 \mathrm{~m}^{2}$.

O delineamento utilizado foi o inteiramente casualizado, com 5 repetições (frascos) contendo 4 brotações cada, arranjados em esquema fatorial $2 \times 4$, sendo dois níveis de irradiância e quatro concentrações de sacarose. Após 4 semanas, foram avaliados: números de raízes principais formadas (não foram consideradas as radicelas), comprimento das três maiores raízes principais (medidas com o auxilio de régua milimetrada), massa fresca total das plantas (planta inteira), além da determinação da clorofila total $(\mathrm{A}+\mathrm{B})$.

Para a determinação dos teores dos pigmentos fotossintéticos, retiraram-se três discos foliares com $1 \mathrm{~cm}$ de diâmetro das folhas de A. bracteatus, os quais foram imersos em $5 \mathrm{~mL}$ de Dimetilsulfóxido (DMSO) por um período de 30 horas. Posteriormente, foram determinadas as leituras da densidade ótica a 470, 663 e $645 \mathrm{~nm}$. Para a obtenção da massa seca, os discos foliares foram, após a extração dos pigmentos, secados por 24 horas em estufa a $\pm 70^{\circ} \mathrm{C}$. Os teores de clorofila foram expressos em $\mathrm{mg} \mathrm{g}^{-1}$ MS (matéria seca), e calculados de acordo com as equações de Arnon (1949) e Lichtenthaler (1987) .

Após 4 semanas de cultivo in vitro sob as condições descritas, e procedidas as avaliações em laboratório, as plantas foram lavadas em água deionizada para retirada do excesso de meio de cultura e transferidas para a casa de vegetação em bandejas de isopor, contendo células individualizadas com o substrato Plantmax $\mathrm{HT}^{\circledR}$, e mantidas sob nebulização intermitente.

A análise estatística foi feita por meio do programa MSTACT $^{\circledR}$, versão 2.10, com análise de variância e comparação de médias pelo Teste de Tukey, ao nível de $5 \%$ de probabilidade.

Houve interação entre os fatores avaliados (irradiância e concentração de sacarose) para as variáveis número de raízes formadas e comprimento médio das 3 
maiores raízes. Na maior irradiância $\left(66,9 \mu \mathrm{mol} \mathrm{m-2} \mathrm{s}^{-1}\right)$, a maior concentração de sacarose apresentou diferenças estatísticas significativas em relação às demais, atingindo as maiores médias tanto para número de raízes formadas como para o comprimento médio. Já para a menor irradiância $\left(22,9 \mu \mathrm{mol} \mathrm{m} \mathbf{-}^{2} \mathrm{~s}^{-1}\right)$, os resultados obtidos com as concentrações de 0 e $10 \mathrm{~g} \mathrm{~L}^{-1}$ foram diferentes entre si para o número de raízes formadas, sendo que, para a variável comprimento médio das raízes, as diferentes concentrações de sacarose forneceram resultados semelhantes (Tabela 1).

Ocorreu semelhança no número de raízes formadas entre os dados obtidos para a testemunha e a concentração de $20 \mathrm{~g} \mathrm{~L}^{-1}$ de sacarose nas duas irradiâncias testadas e, para a concentração de $10 \mathrm{~g} \mathrm{~L}^{-1}$, a irradiância de $22,9 \mu \mathrm{mol} \mathrm{m}^{-2} \mathrm{~s}^{-1}$ foi mais eficiente, ocorrendo o inverso na concentração de $30 \mathrm{~g} \mathrm{~L}^{-1}$.

No presente trabalho, o maior número médio de raízes formadas $(7,2)$ foi observado no tratamento com maior concentração de sacarose exógena e maior irradiância (Tabela 1). Nesse tratamento, as raízes apresentavam-se mais vigorosas. Os dados obtidos são concordantes com as afirmações de vários autores de que a presença de carboidrato é essencial para o enraizamento in vitro de muitas espécies (Sriskandaraja \& Mullins, 1981; George \& Sherrington, 1984; Grattapaglia \& Machado, 1990).

Testando diferentes concentrações de sacarose no enraizamento in vitro de morangueiro, Calvete et al.
(2002) observaram que o aumento da concentração de sacarose promoveu um incremento de biomassa, tanto na parte aérea como no sistema radicular, das mudas de morangueiro (Fragaria vesca L.). Entretanto, para a menor irradiância, a maior concentração de sacarose não apresentou o mesmo efeito, sendo a maior média obtida no tratamento com $10 \mathrm{~g} \mathrm{~L}^{-1}$. Essa discrepância pode estar relacionada com a maior probabilidade de erro que as avaliações de variáveis quantitativas geralmente apresentam.

Para o comprimento médio das três maiores raízes (Tabela 1), a maior média $(1,4 \mathrm{~cm})$ foi obtida também com 30 $\mathrm{g} \mathrm{L}^{-1}$ de sacarose sob a maior irradiância $\left(66,9 \mu \mathrm{mol} \mathrm{m} \mathrm{m}^{-2} \mathrm{~s}^{-1}\right)$, indicando uma resposta positiva da planta em relação ao suprimento de sacarose, sugerindo que o local de produção do carboidrato foi efetivamente utilizado na formação de raízes. Embora as raízes formadas sob os tratamentos de pré-aclimatização mencionados acima fossem em maior número e com maior comprimento, isto não significou maior taxa de sobrevivência. Nas demais concentrações de sacarose, os resultados de sobrevivência foram semelhantes sob os dois níveis de irradiância.

Não houve interação entre os dois fatores estudados para a variável massa fresca. Entretanto, houve diferença significativa entre os resultados obtidos nos dois tratamentos luminosos, onde o maior valor médio de massa fresca foi observado no tratamento com menor irradiância (Tabela 2).

Tabela 1 - Número e comprimento médio das raízes formadas em explantes de Ananas bracteatus cultivados in vitro em função da irradiância e da concentração de sacarose no meio de cultura.

\begin{tabular}{|c|c|c|}
\hline \multicolumn{3}{|c|}{ Número médio de raízes formadas } \\
\hline \multirow{2}{*}{ Concentração de sacarose $\left(\mathrm{g} \mathrm{L}^{-1}\right)$} & \multicolumn{2}{|c|}{ Irradiância } \\
\hline & $22,9 \mu \mathrm{mol} \mathrm{m} \mathrm{s}^{-2}$ & $66,9 \mu \mathrm{mol} \mathrm{m} \mathrm{s}^{-2}$ \\
\hline 0 & $2,2 \mathrm{~b} \mathrm{~A}$ & $1,6 \mathrm{~b} \mathrm{~A}$ \\
\hline 10 & 5,4 a A & $2,6 \mathrm{~b} \mathrm{~B}$ \\
\hline 20 & $4,4 \mathrm{ab} A$ & $2,6 \mathrm{~b} \mathrm{~A}$ \\
\hline 30 & $4,6 \mathrm{ab} \mathrm{B}$ & 7,2 a A \\
\hline C.V $(\%)$ & \multicolumn{2}{|c|}{38,9} \\
\hline \multicolumn{3}{|c|}{ Comprimento médio das raízes $(\mathrm{cm})$} \\
\hline 0 & 0,9 a A & $0,5 \mathrm{~b} \mathrm{~A}$ \\
\hline 10 & 0,7 a A & $0,3 \mathrm{~b} \mathrm{~A}$ \\
\hline 20 & 0,8 a A & $0,5 \mathrm{~b} \mathrm{~A}$ \\
\hline 30 & 0,6 a B & 1,4 a A \\
\hline $\mathrm{CV}(\%)$ & \multicolumn{2}{|c|}{38,7} \\
\hline
\end{tabular}

Médias seguidas por letras distintas, minúsculas na vertical, e maiúsculas na horizontal, dentro de cada irradiância testada diferem entre si, em nível de 5\% de probabilidade pelo teste de Tukey. CV corresponde ao coeficiente de variação dos dados. 
Observou-se um aspecto de queima nas folhas das plantas mantidas sob alta irradiância, podendo este fato ter ocasionado redução na área foliar e, consequentemente, redução em sua massa. Para a concentração de sacarose, também houve diferença significativa entre os tratamentos estudados, sendo que as maiores médias de massa fresca foram observadas nos tratamentos com 10, 20 e $30 \mathrm{~g}$ de sacarose, respectivamente.

Os níveis crescentes de sacarose resultaram no aumento da biomassa in vitro de abacaxi ornamental. Contrariamente, as plantas que foram submetidas à ausência de sacarose apresentaram o menor valor de massa fresca. Esses resultados podem estar relacionados com o número de raízes e, consequentemente, com a quantidade de água absorvida, visto que os explantes submetidos ao cultivo com ausência de sacarose apresentaram os menores números de raízes.

Souza et al. (2007) ao estudarem a influência da sacarose no enraizamento in vitro do porta-enxerto de macieira, também encontraram maior acúmulo de massa fresca na presença de sacarose, superior quatro vezes quando comparado com a ausência dessa fonte de carbono no meio de cultura. Os valores médios do número e comprimento de raízes também foram superiores nesta condição, semelhantemente ao ocorrido, de forma geral, neste estudo.

Apesar de não ter ocorrido interação entre os fatores, pode-se observar que a menor irradiância favoreceu o maior acúmulo de clorofila total (Tabela 3). Esse resultado corrobora com a afirmação de Ferraz \& Silva (2001) que dizem que, de uma forma geral, a clorofila e os carotenóides tendem a aumentar com a redução da intensidade luminosa.

Isso pode ser atribuído ao fato de Ananas bracteatus ser uma planta de sol, e uma das características fotossintéticas das plantas de sol é a menor quantidade de moléculas de clorofila por cloroplasto, principalmente a clorofila $b$, uma vez que essas plantas não necessitam investir na produção de pigmentos coletores de energia luminosa, em um ambiente saturado por luz (Salisbury \& Ross, 1991).

Alguns estudos também relatam a observação de teores de clorofilas, por unidade de massa seca, mais elevados em folhas sombreadas em relação àquelas expostas ao sol, e uma razão clorofila $a / b$ maior para folhas de sol (Lei \& Lechowicz, 1998; Scalon et al., 2003). Isso pode explicar o fato das plantas terem acumulado mais clorofila em menores irradiâncias.

Embora as plantas que permaneceram sob menor irradiância tenham apresentado número e comprimento de raízes estatisticamente inferiores às plantas sob maior irradiância, o maior acúmulo dos pigmentos clorofilianos provavelmente contribuiu para que as plantas, durante a aclimatização, apresentassem sobrevivências semelhantes (Tabela 4). Estes pigmentos possivelmente favorecem a realização da fotossíntese nas plantas submetidas a tratamento com menor irradiância, o que provavelmente contribuiu para acumular biomassa e promover o desenvolvimento do sistema radicial, possibilitando ao final da aclimatização a semelhança entre as taxas de sobrevivência encontradas no presente estudo.

Houve de forma significativa um menor acúmulo de clorofila nas plantas cultivadas na ausência de sacarose, diferentemente do relato de Pasqual (2001) que afirma que a taxa fotossintética é estimulada sob condições de baixas concentrações de sacarose. Mesmo as plantas apresentando uma taxa fotossintética baixa em condições in vitro, o suprimento de carbono exógeno provavelmente interferiu de forma positiva em rotas metabólicas envolvidas na produção de clorofila, resultando no acúmulo observado.

Não ocorreu interação entre os fatores estudados quanto à taxa de sobrevivência das plantas em casa de vegetação, sendo a mesma satisfatória (Tabela 4). Analisando os fatores separadamente, percebe-se que as irradiâncias testadas, embora não diferindo entre si, resultaram em porcentagens de sobrevivência menores quando comparadas com as diferentes concentrações de sacarose, sugerindo que aquele fator possui grande influência durante a pré-aclimatização, que se reflete na sobrevivência ao final da aclimatização. Esta observação difere dos resultados de Gribaudo \& Fronda (1993), os quais afirmam que uma das formas de facilitar a aclimatização das plântulas seria por meio do aumento da irradiância, que promoveria a fotossíntese.

Para as diferentes concentrações de sacarose houve diferença estatística significativa entre o tratamento controle e os demais $\left(10,20\right.$ e $\left.30 \mathrm{~g} \mathrm{~L}^{-1}\right)$. O controle apresentou menor taxa de sobrevivência (50\%) em comparação com os outros tratamentos. Diferentemente, Augusto et al. (2006), ao compararem a presença e a ausência de sacarose no meio de enraizamento de amoreira-preta (Rubus sp.), constataram que não houve diferença com relação ao enraizamento e sobrevivência das plantas após a aclimatização. Já Guerra et al. (1999) obtiveram 95\% de sobrevivência após 30 dias da aclimatização com abacaxi comestível [Ananas comosus (L.) Merr.], entretanto, os brotos foram cultivados em meio de enraizamento suplementado com $30 \mathrm{~g} \mathrm{~L}^{-1}$ de sacarose. 
Tabela 2 - Massa fresca total média de plantas de Ananas bracteatus sob diferentes irradiâncias em sala de crescimento e concentrações de sacarose no meio de cultura.

\begin{tabular}{cc}
\hline Irradiância & Massa fresca média $(\mathrm{g})$ \\
\hline $22,9 \mu \mathrm{mol} \mathrm{m}^{-2} \mathrm{~s}^{-1}$ & $1,20 \mathrm{a}$ \\
$66,9 \mu \mathrm{mol} \mathrm{m}^{-2} \mathrm{~s}^{-1}$ & $1,06 \mathrm{~b}$ \\
\hline Concentração de sacarose $\left(\mathrm{g} \mathrm{L}^{-1}\right)$ & Massa fresca média $(\mathrm{g})$ \\
\hline 0 & $0,94 \mathrm{~b}$ \\
10 & $1,11 \mathrm{ab}$ \\
20 & $1,16 \mathrm{ab}$ \\
30 & $1,31 \mathrm{a}$ \\
\hline $\mathrm{CV}(\%)$ & 17,9
\end{tabular}

Médias seguidas por letras distintas na vertical, dentro de cada massa fresca diferem entre si, em nível de 5\% de probabilidade pelo teste de Tukey.

Tabela 3 - Teores médios de clorofilas A + B em plantas de Ananas bracteatus cultivadas in vitro sob diferentes irradiâncias e concentrações de sacarose no meio de cultura.

\begin{tabular}{|c|c|}
\hline Irradiância & Clorofila $\mathrm{A}+\mathrm{B}\left(\mathrm{mg} \mathrm{g}^{-1} \mathrm{MS}\right)$ \\
\hline $22,9 \mu \mathrm{mol} \mathrm{m}^{-2} \mathrm{~s}^{-1}$ & $11,0 \mathrm{a}$ \\
\hline $66,9 \mu \mathrm{mol} \mathrm{m} \mathrm{s}^{-2}$ & $9,3 \mathrm{~b}$ \\
\hline \multicolumn{2}{|c|}{ Concentração de sacarose $\left(\mathrm{g} \mathrm{L}^{-1}\right)$} \\
\hline 0 & $6,5 \mathrm{~b}$ \\
\hline 10 & $12,1 \mathrm{a}$ \\
\hline 20 & $10,7 \mathrm{a}$ \\
\hline 30 & $11,4 \mathrm{a}$ \\
\hline CV (\%) & 13,5 \\
\hline
\end{tabular}

Médias seguidas por letras distintas na vertical, dentro de cada teor de clorofila total diferem entre si, em nível de $5 \%$ de probabilidade pelo teste de Tukey.

Tabela 4 - Porcentagem de sobrevivência de Ananas bracteatus aos 30 e 60 dias do transplante para casa de vegetação após tratamentos de pré-aclimatização em sala de crescimento.

\begin{tabular}{ccc}
\hline & \multicolumn{2}{c}{ (\%)Sobrevivência } \\
\hline Irradiância & 30 dias & 60 dias \\
\hline & & $87 \mathrm{a}$ \\
$66,9 \mu \mathrm{mol} \mathrm{m}^{-2} \mathrm{~s}^{-1}$ & $85 \mathrm{a}$ & $85 \mathrm{a}$ \\
\hline Concentração de sacarose $\left(\mathrm{g} \mathrm{L}^{-1}\right)$ & & $50 \mathrm{~b}$ \\
\hline 0 & $50 \mathrm{~b}$ & $100 \mathrm{a}$ \\
20 & $100 \mathrm{a}$ & $95 \mathrm{a}$ \\
30 & $95 \mathrm{a}$ & $100 \mathrm{a}$ \\
\hline $\mathrm{CV}(\%)$ & $100 \mathrm{a}$ & 17,45 \\
\hline
\end{tabular}

Médias seguidas por letras distintas na vertical, dentro de cada porcentagem de sobrevivência diferem entre si, em nível de 5\% de probabilidade pelo teste de Tukey. 
No presente estudo, as demais concentrações de sacarose foram semelhantes estatisticamente, proporcionando taxas de sobrevivência elevadas (95 a $100 \%$ ) e constantes, tanto com 10, 20 e $30 \mathrm{~g} \mathrm{~L}^{-1}$ de sacarose. Isso demonstra que o aporte de sacarose no meio de enraizamento da espécie em questão é fundamental para uma boa taxa de sobrevivência, sendo este componente essencial ao meio de cultura. Além disso, tais concentrações supriram a necessidade de carboidrato, durante a aclimatização, permitindo que a planta se adaptasse ao ambiente ex vitro e iniciasse o mecanismo autotrófico.

Com base neste estudo, conclui-se que durante o enraizamento in vitro de plantas de abacaxi ornamental, as irradiâncias testadas não influenciaram a taxa de sobrevivência após a aclimatização; as concentrações superiores a $10 \mathrm{~g} \mathrm{~L}^{-1}$ permitem uma elevada taxa de sobrevivência, diferentemente dos explantes cultivados com ausência de sacarose; ao final de 30 dias em casa-devegetação, a taxa de sobrevivência das plantas é satisfatória e constante até os 60 dias.

\section{REFERÊNCIAS BIBLIOGRÁFICAS}

ARNON, D.I. Copper enzymes in isolated chloroplast: polyphenoloxidase in Beta vulgaris. Plant Physiology, Rockville, v.24, n.1, p.1-15, 1949.

ATROCH, E.M.A.C.; SOARES, A.M.; ALVARENGA, A.A.; CASTRO, E.M. Crescimento, teor de clorofilas, distribuição de biomassa e características anatômicas de plantas jovens de Bauhinia forficata Link submetidas à diferentes condições de sombreamento. Ciência e Agrotecnologia, Lavras, v.25, n.4, p.853-862, 2001.

AUGUSTO, C.S.S.; BIASI, L.A.; TELLES, C.A. Enraizamento e aclimatização de plantas micropropagadas de amoreira-preta CV. BRAZOS. Revista Brasileira de Fruticultura, Jaboticabal, v.28, n.3, p.473-476, 2006.

BAIMA, S. Sistema de Informação Gerencial Agrícola - SIGA. Belém: SEAGRI, 2005.

BORGES, N.S.S.; CORREIA, D.; ROSSETTI, A.G. Influência do meio bifásico na multiplicação de gemas e no alongamento de brotos in vitro de Ananas lucidus Miller. Revista Brasileira de Horticultura Ornamental, Campinas, v.9, n.1, p.37-44, 2003.

CALVETE, E.O.; KÄMPF, A.N.; SUZIN, M.

Concentração de sacarose no enraizamento in vitro de morangueiro. Horticultura Brasileira, Brasília, v.20, n.2, p.186-191, 2002.

CORREIA, D.; OLIVEIRA, P.M.A.; RIBEIRO, K.A.; SILVEIRA, M.R.S. Avaliação da multiplicação in vitro do abacaxi ornamental (Ananas lucidus Miller). Fortaleza: Embrapa Agroindústria Tropical, 1999. (Pesquisa em Andamento, 56).

ECONOMOU, A.S.; READ, P.E. Light treatments to improve efficiency of in vitro propagation systems. HortScience, Alexandria, v.22, n.5, p.751-754, 1987.

FERRAZ, K.K.F.; SILVA, D.M. Avaliação ecofisiológica do crescimento inicial de espécies florestais usadas na recuperação de áreas degradadas: II., Calliandra calothyrsus Meisn. In: CONGRESSO BRASILEIRO DE FISIOLOGIA VEGETAL, 8., 2001, Ilhéus. Resumos... Ilhéus: Sociedade Brasileira de Fisiologia Vegetal, 2001. CD-ROM.

GEORGE, E.F.; SHERRINGTON, P.D. Plant propagation by tissue culture. Eversley: Exegetics, 1984.

GUERRA, M.P.; VESCO, L.L.; PESCADOR, R.; SCHUELTER, A.R.; NODARI, R.O. Estabelecimento de um protocolo regenerativo para a micropropagação do abacaxizeiro. Pesquisa Agropecuária Brasileira, Brasília, v.34, n.9, p.1557-1563, 1999.

GRATTAPAGLIA, D.; MACHADO, M.A. Micropropagação. In: TORRES, A.C.; CALDAS, L.S. Técnicas e aplicações da cultura de tecidos de plantas. Brasília: ABCTP/Embrapa-CNPH, 1990. p.99-169, 433p.

GRIBAUDO, I.; FRONDA, A. L'ambientamento delle piante frutticole micropropagate. Rivista di Frutticolture, Paris, v.1, p.75-79, 1993.

HAZARIKA, B.N. Morpho-physiological disorders in in vitro culture of plants. Scientia Horticulturae, New Delhi, v.108, p.105-120, 2006.

KOZAI, T. Micropropagation under photoautotrophic conditions. In: DEBERGH, P.C.; ZIMMERMAN, T.H. Micropropagation technology and application. Dordrecht: Kluwer, 1991. 484p.

LEI, T.T.; LECHOWICZ, M.J. Diverse responses of maple saplings to forest light regimes. Annals of Botany, London, v.82, n.1, p.9-19, 1998. 
LICHTENTHALER, H.K. Chlorophylls and carotenoids: pigments of photosynthetic biomembranes. In: Methods in enzymology. New York: Academic, 1987. p.350-382.

MURASHIGE, T.; SKOOG, F. A revised medium for rapid growth and bioassays with tabacco tissue cultures. Physiologia Plantarum, Copenhagen, v.15, p.473-497, 1962.

PASQUAL, M. Meios de cultura. Lavras: UFLA/FAEPE, 2001. 74p.

SALISBURY, F.B.; ROSS, C.W. Plant Physiology. 3.ed. Belmont: Wadsworth, 1991. 692p.

SCALON, S.P.Q.; MUSSURY, R.M.; RIGONI, M.R.; SCALON FILHO, R. Crescimento inicial de mudas de Bombacopsis glabra (Pasq.) A. Robyns sob condição de sombreamento. Revista Árvore, Viçosa, v.27, n.6, p.753-758, 2003.

SILVA, A.L.L.; FRANCO, E.T.H.; WALTER, J.M.; BISOGNIN, D.A.; CALGAROTO, N.S. Aclimatização de clones de Dyckia Marítima em diferentes substratos BROMELIACEAE. Revista Brasileira de Agrociência, Pelotas, v.12, n.4, p.495-498, 2006.

SOUZA, J.A.; DONINI, L.P.; SILVA, L.C.; CORRÊA, M.G.S. Enraizamento in vitro do porta-enxerto de macieira - M9 em função da vedação, sacarose e material de suporte no meio de cultura. Scientia Agraria, Curitiba, v.8, n.2, p.161-164, 2007.

SRISKANDARAJAH,S.;MULLINS,M.G. Micropropagation of Granny Smith apple: factors affecting root formation "in vitro". Journal of Horticultural Science, Ashford, v.56, n.1, p.71-72, 1981. 